\title{
Redefining the Smart City concept: the importance of humanizing 'Intelligent' cities
}

\author{
Raquel Pérez-del Hoyo, Megan Claire Lees \\ Departamento de Edificación y Urbanismo. Universidad de Alicante. Alicante, Spain \\ E-mail: perezdelhoyo@ua.es, megan.lees.ml@gmail.com
}

\begin{abstract}
Within the context of the changes provoked by globalization and overurbanization in recent decades, cities face the challenge of conceiving new and more competitive and sustainable development models. To this effect, the Smart City is proposed as a new model of urban development. However, the concept of Smart City has developed in such a way (in most cases completely alien to the area of Urbanism) that, in a way, cities have begun to face the risk of losing their soul. Clear examples of this are the new 'intelligent' cities created from scratch as mere efficient functional structures, without history and even without inhabitants, and lacking understanding of the very complexity and nature of cities, which are first and foremost dynamic places to be experienced. This is why, one of the main challenges with which Urbanism of the 21st century is confronted, is to work on redefining the concept of Smart City, redirecting its development to humanize and give soul back to these near future 'intelligent' cities. In this direction, the main objective of this research is to contribute as urban planners in this redefinition of the concept of Smart City as a new model of urban development. From the work carried out, the proposal of a model, sensitive to the environment (natural, cultural and urban) but above all a model focused on people, their preferences, opinions and needs is concluded.
\end{abstract}

Keywords: Smart City, Inclusive City, Sustainable City, Urban

Development Model, Humanizing Cities.

\section{Introduction}

With the multitude of people living in cities today, over $50 \%$ of the world population, and considering that this proportion will continue increasing until reaching at least $70 \%$ in the next thirty years (Vojnovic, 2014), the quality of life and well-being of citizens are compromised and adversely impacted. Demographic changes and their consequences, such as urban gentrification, social exclusion, sustainability of resources, health services, and urban security, among others, are urban problems increasingly faced by cities. That is why the global cities of the 21 st century are constantly seeking a solution that guarantees the satisfaction of these needs as a priority (Glasmeier and Christopherson, 2015).
The extraordinary development of Information and Communication Technology - ICT - has fostered a society that is increasingly connected and able to participate and demand its needs within the field of urban development (Dodgson and Gann, 2011) (Townsend, 2013). Consequently, the new urban methodologies lead to a new model based on the integration of technologies in urban infrastructures to facilitate the functioning and efficiency of an expanding city and also to take care of the valuable aspects of the city (Hollands, 2008) (Stimmel, 2016).

The true protagonists of a future urban 'intelligence' are not innovative technologies but citizens who are able to take advantage 
of those technologies (Oliveira, 2015). The true potential lies in participatory systems in which citizens and communities are able to interact with superior authorities and entities in a collaborative way, exploiting the power of innovative services designed focusing on users (Concilio and Rizzo, 2016).

\section{Background: Around the concept of Smart City}

It is difficult to understand the concept of Smart City precisely after the important diffusion and uncontrolled use of the term since its first appearance, which has led to the current situation characterized by the lack of clarity and thoroughness of the different initiatives. Nowadays, in many circumstances, the concept of Smart City is nothing more than an ambiguous label that ends up being applied within a very wide field of cases (Angelidou, 2014).

Therefore, in many areas of knowledge, the concept of Smart City has lost relevance and has diverted from its own context and purpose. Such is the case of the specific field of urbanism, in which it has generally become an empty term and without content. As a result, it is commonly accepted by researchers in the field of urbanism that there is no precise definition of Smart City, while other thinkers take a step further and have developed theories about how the intelligent city is nothing more than a destructive movement (Ojo, Dzhusupova and Curry, 2016).

There are many conflicting ideas about the origins of the "Smart City" concept, so it is complicated to specify and date a first case or emergence of the movement, but it has been concluded that Americans can be credited in the 1970s by looking for models that would coordinate urban growth and act against extensive growth that manifested itself in an uncontrolled way, leading to the emergence of various urban problems That would lead to an analysis and investigation of the North American cases and the consequent evaluation and implementation of solutions.

It is really from the 90's that the concept is introduced to highlight the importance of ICT in new urban growth (Al-Nasrawi, Adams and El-Zaart, 2016), especially thanks to the advance of the Internet that had previously been simply an instrument in the scientific community and became a service of easy access that revolutionised the models of social interaction (Neirotti et al., 2014).

It is proposed more often today as a potential solution to urban problems and conflicts that often arise in a contemporary city, especially in the face of the global population movements and the tendency to live more and more the world population in a city, producing in turn a lack of resources, a new challenge and the need to create a more sustainable urban environment. It includes within this solution the care of the areas of health services, transport, infrastructure of communications, systems and energy resources and environmental sustainability, above all. The definition of the Smart City sometimes includes the set of these services and infrastructures that manage to be based on the computer and communicative technologies and a more efficient and fluid urban functioning. However, very often the label of 'Smart City' is put in use to identify the technological transformations of an aspect or core system within a city such as economy, government, transportation, environment, etc.

In general, the services included in smart initiatives are governed by a Interconnected network of domains or essential ideals 'Smart'. These concepts are: Smart Economy, Smart People, Smart Governance, Smart Mobility, Smart Living, Smart Environment.

\section{Objectives and Methodology}

The objective of this work is to study a series of cases of intelligent cities and the factors involved in their development, to determine which are the most efficient methods used so far and to establish bases and guidelines to optimise the potential of our future cities, always with the maximum benefit for the people who are going to experience and live in that community. Simultaneously, a research on the historical values and heritage of a city is proposed, in which the importance of preserving the historic footprint of a city in 
its development, with the implementation of new technologies, systems and services, is discovered. In any case, the study is based on existing cases.

\section{Study of existing cases}

As a background, the first Smart City can be dated in 1854 (Copeland, 2016). It may have been London in the year that there was an outbreak of cholera in the Soho district causing some 616 deaths in just one month. This case explains a first example of a solution to a civic dilemma, through the collection and use of data. A map of the area was drawn up marking the geographical points where there were deaths (Figure 1), from which it was deduced that all the victims were near the same water well. In this sense, Copeland argues that the 'Smart City' concept has less to do with innovative technologies and futuristic visions of automatic cities, and the concept of 'internet of things', stating that a Smart City is the one that implements the collection of data and research to solve urban problems and improve their functionality, although this may foster a social conflict.

In the current context of the wide diversity

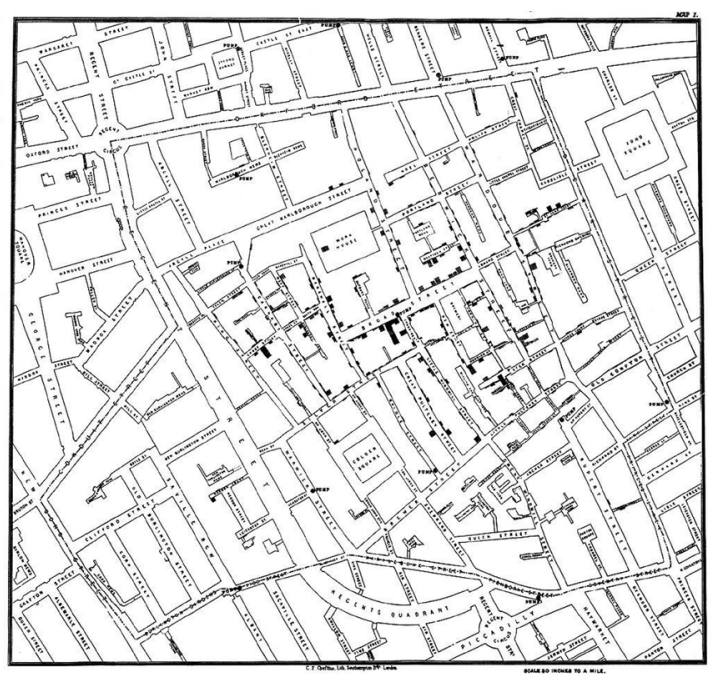

Figure 1. John Snow's Map. Collection of data of the city of London in 1854. Source: (Snow, 1855). of urban 'smart' applications, on the one hand the incentives of a development based on the integration and application of broad technological innovations seeking the modernization in the historical cities are highlighted. Some experts maintain a functional city vision, establishing their bases in the abundant use of information and communication technologies with the objective of creating an efficient environment for the development of human life, while others establish their principles around the accessibility and inclusion of the citizens themselves, whose quality of life and satisfaction takes a priority position in technological innovation processes, with results more controlled and thought than in the previous case, thus promoting a new urban sustainability.

On the other hand, at the other extreme, there is a relatively recent and growing tendency of urbanizations based on the occupation of nonurbanized land, as descendants of a host city under optimum economic conditions seeking to build an ideal city from a fabric intact. In recent years there has been a great push and advance in the development of Smart Cities in this most literal sense. Particularly in the Middle East and Korea where it could be said that the term has been pushed to the limits of technological advances with the purpose of reconceiving the operation of the cities in an experimental way, driven by a futuristic vision and creating models from scratch for the future urban development that is beginning to spread in other parts of the world.

These prototype cities are driven by contemporary attempts to develop a new 'experimentation' of the Smart City from scratch, revealing themselves as areas of new construction, without residents or previous infrastructure that make up the urban layout. To this end, the political routines that are put in place and the specific regulations are flexible in order to facilitate the execution of this 'experimentation'. Existing cases show that the objectives of these cities include the implementation of interventions on a blank canvas in which urban systems and infrastructures can be integrated with the greatest ease and flexibility through ICT technology from the outset. 


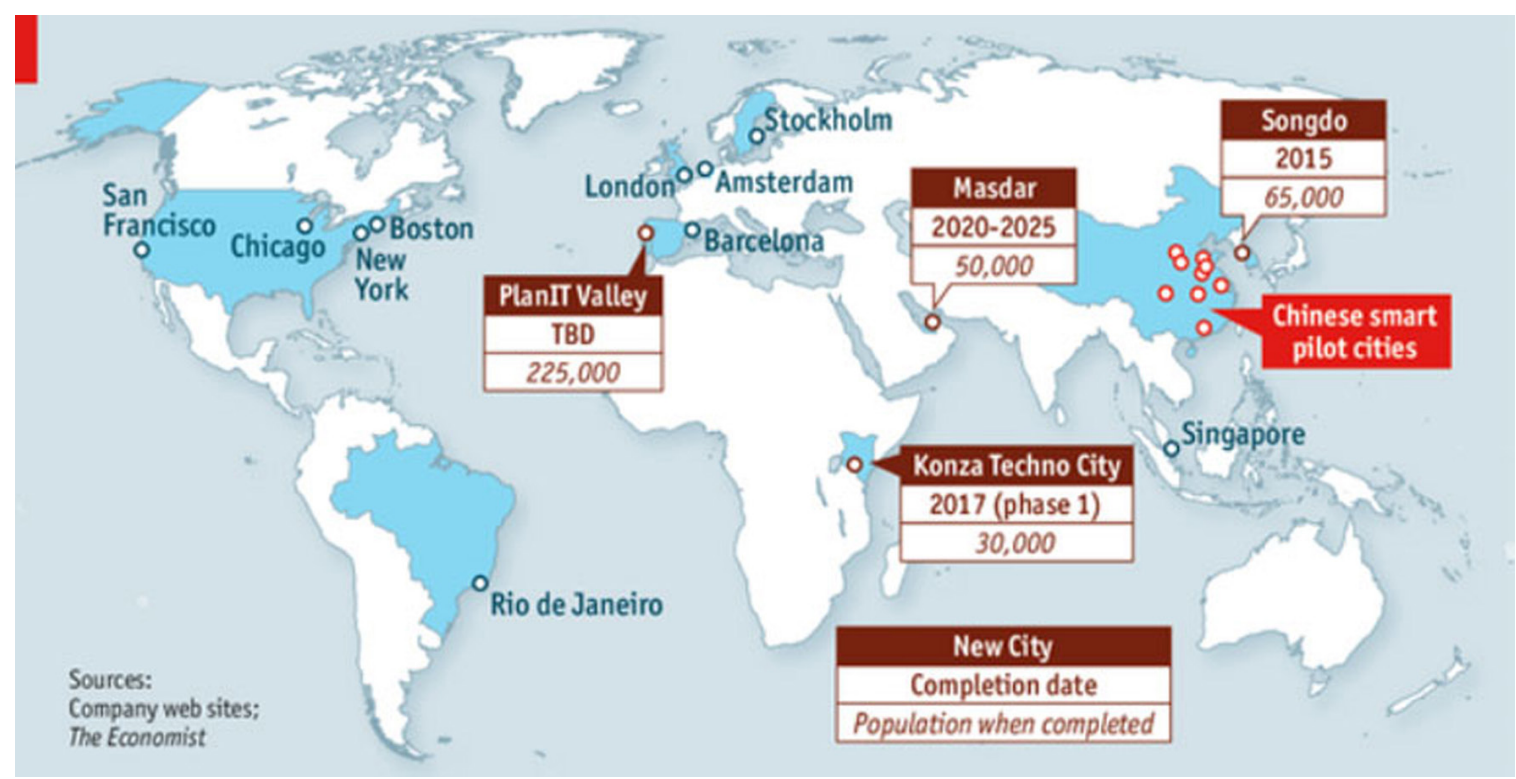

Figure 2. Location of prototype cities in the areas of East, South Africa, and Europe. Source: Company web sites; The Economist.

The main cities of this type to be highlighted can be located in the areas of East, South Africa, and Europe, which started to project from the year 2000 (Figure 2).

The design and construction of a city from scratch has the advantage of avoiding costly technological adaptations, encouraging more capacity to encourage the internet of things and the introduction of more innovative techniques. This initiative is attractive because of the idea of avoiding the complexities that entail the transformations in the existing cities, and the alteration in the daily processes to which the citizenship is already accustomed. It seems that the essence of these new cities ends up winning against the traditional cities with the isolated solutions that can provide the internet of things, introducing key tools for the reduction of complexity, costs, processes, and the time required, for the development of intelligent solutions in a city.

Developing countries are in an optimal position to take advantage of these prototype cities. The lack of adequate infrastructure has prevented good development so far, but starting from scratch opens up new opportunities. The city is designed to create a new experience specifically for its citizens with systems and services that achieve optimum efficiency and sustainability throughout the city. Starting from zero allows these amenities to be fully integrated into one network, creating the city's supporting skeleton. Every component, each sensor or monitor of water circulation, traffic, lighting or security, would grow as a result of this network.

A characteristic of prototype cities is to depend on a neighboring city or region, the 'host' city, in its political, legal, and above all financial aspects. The new base on which it operates is perceived as a perfect opportunity to integrate new systems more easily, as a test, thus allowing experimentation with the most advanced innovations, as well as integrating new infrastructures without the inconvenience of modifying anything existing. Likewise, there is a certain freedom in the creation of elementary infrastructures of the city, both physical and socio-political, without being governed by precepts or previous regulations or social contexts. They are faced with the possibility of playing with new political systems to analyse impacts and reactions in the public domain, intensifying the emergence of political conflicts not only in the local context but also as a side effect in the host city.

However, this is done without the possibility of a previous analysis of the social impact and the implications that would result from such extreme interventions, so that the systems 
can manifest themselves prematurely and ambitiously, without having been properly prepared for their integration into the society, utopian infrastructures that risk straying too far from reality due to the lack of antecedents that are found in traditional cities. In addition, these interventions are conditioned by a high knowledge of the advanced technologies, implying the lack of the possibility of public inclusion. The management of new systems and technologies so advanced, in order to guarantee the correct functioning of services, induces an idealistic 'functional city' aspect, unlike a city to be lived, with a contradictory aspect that is public exclusion; an aspect that the "smart" movement seeks to avoid from the beginning. Therefore, the advantages of a 'from scratch' development are at the same time its greatest limitations. Three examples are given below.

Songdo, South Korea (Figure 3).- We are located on an island in the South Korea area, about $50 \mathrm{~km}$ from the city of Seoul, in front of the nearest city, Incheon. It is planned to occupy a territory of some 5,300 hectares once completed the execution, which is still in process although it 'opened' in 2009. The expected completion date was 2015 . The main innovations projected for the city include the integration of an international business district, residential areas, international university campuses, science parks and technological amenities. Its main visionary ideal is the ubiquitous city, or U-city, which refers to the idea of total interconnection of information systems, including technological integration in the homes themselves. The main host entities of Songdo are the city of Incheon, the national government, IFEZ (Incheon Free Economic Zone), Gale, POSCO and Cisco. Technological innovations include the Cisco 'TelePresence' system and the radio frequency technology, RFID technology (Integrated Operations Centre). In early 2000, the city of Incheon was declared a free economic zone, and the Songo project became one of the main pillars of its investment strategy, with a visionary goal of attracting international companies, universities and expatriate workers. Songdo's first technological visions date back to 2004 when it was selected as part of the Korean initiative of ubiquitous city, or 'U-city' and as a testing ground for these new technologies and the integration of them into everyday life. By using radio frequency identification apparatus systems, smart monitors, data exchange, audio-visual networks and sensors, strategies are proposed that include real-time traffic solutions, health services, crime prevention and environmental information services.

Problems related to data collection, conflicts in the area of privacy and ownership arise, which tend to dominate the debate, thus diverting attention from more delicate issues within the community, including the development of the relationship between companies and the users, as well as the link between the city itself and its socio-political environment.

The neighbouring communities themselves have shown varied opinions on the costs and benefits of the city, which together with the changes in political systems and population uncertainty contribute to the deterioration of social and political support for Songdo,

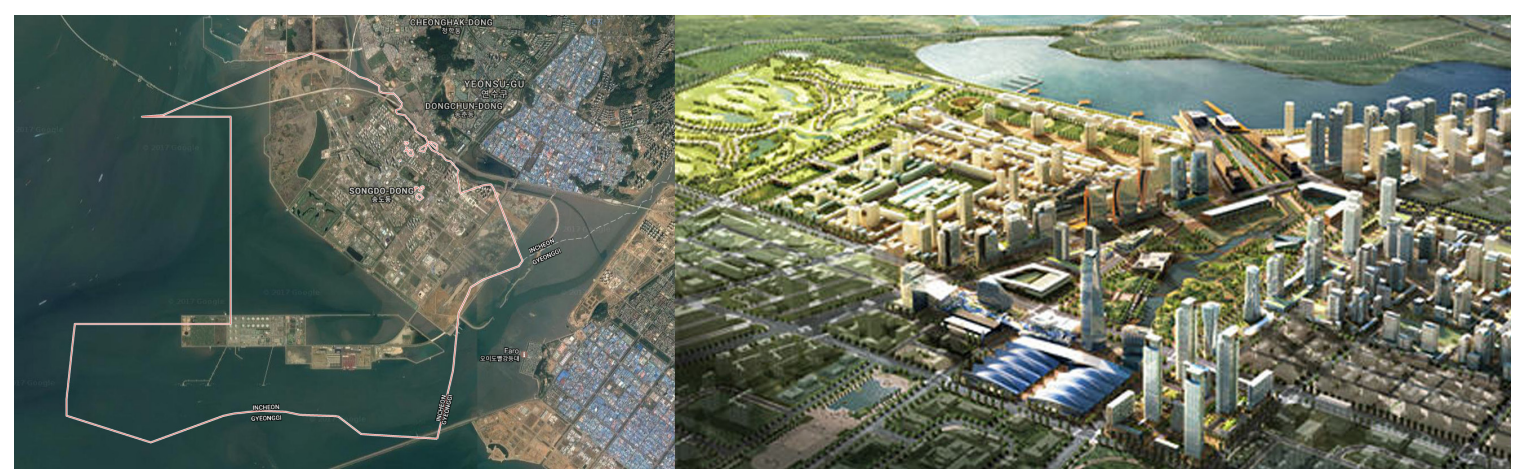

Figure 3. Songdo, South Korea. Sources: Google and ZDNet Korea (http://www.zdnet.co.kr/ news/news_view.asp?artice_id=20111108094612) 
resulting in problems in obtaining financial resources, among other things, implying the lack of guarantee of the durability of 'smart innovations' and the risk of temporality of new technologies.

Masdar City, Abu Dhabi (Figure 4).- The city of Masdar is planned in Abu Dhabi with the help of the British study Foster + Partners as a manifestation of the new technological advances in the innovation of sustainable energy sources that the government wanted to promote. With accommodation for about 40 thousand people, in addition to the 50 thousand workers who would be added daily. Among other incentives, it promises an infrastructure that responds to environmental conditions, which would include regulation of solar energy and moisture to control the desert space that characterizes the area, thus achieving better levels of comfort under unfavorable conditions. It includes the integration of an electric public transport system that traverses the city in such a way as to eliminate any need for its own vehicle for citizens.

PlanIT Valley, Paredes, Porto, Portugal (Figure 5).- To $30 \mathrm{~km}$ of the city of Porto, we located this city in the neighbouring area of the one of Paredes, with a planning of occupation of 1,670 hectares. Urban planning ended in 2009 but the start of its operation was delayed. It is projected with the initiative of research and development city, in addition to implementing prototype services, along with the residential dimension and basic amenities. Its development is based on the notion of "brain city' with an urban structure that resembles the nervous system of the human body. It promotes a technological innovation that includes a city of sensors and 'urban apps'.

Despite the first push, PlanIT is having a hard time getting started, Songdo's u-strategies have lost ground, and overall major technology proposals are starting to be implemented on a smaller scale, less ambitiously, in Smart City initiatives all over the world. They present difficulties in taking care of innovative ecosystems, mastery of corporate technological knowledge, limited user relationships with producing entities, and the tensions that appear with the socio-political areas of the surroundings and with the distances with the system of governance and rulemaking.

\section{Conclusion}

If precisely the concept of Smart City arises in search of a solution to the increasing urban challenges, it is necessary to ask for what purpose these new model cities are being created. Innovations are being integrated for a society that does not yet exist. And as a result, externally developed ideas, visions and technological innovations do not process the necessary adjustment for proper integration and run the risk of being totally dominant, creating a considerable division between the producing entity and the users (citizens), contradicting thus one of the main objectives of the 'Smart' initiative that is the public inclusion and obtaining totally paradoxical results.

Over time and above all due to the great technological advances that are available to us, an endless number of models have emerged

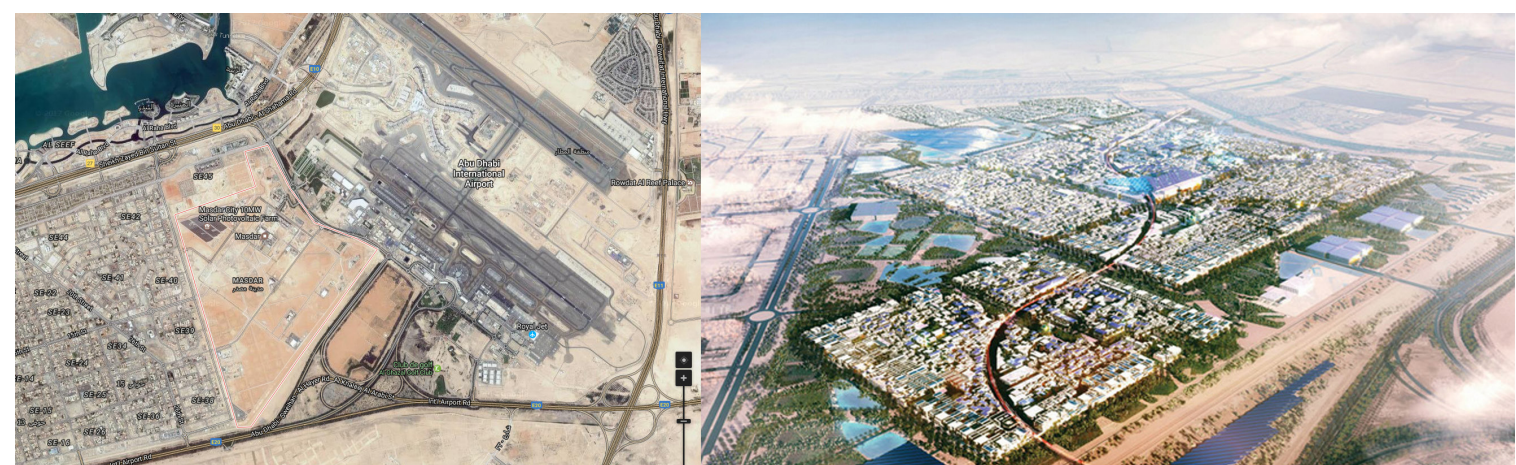

Figure 4. Masdar City, Abu Dhabi. Sources: Google and Blogsmartcities (WordPress) (https://blogsmartcities.wordpress.com/2014/04/30/masdar-city-die-okostadt-in-derwuste/) 
that aim to pick up the large defining blocks to succeed in the development and evolution of 'Smart' incentives for the city and its citizenship. These development bases regulate the methodologies of the actions by means of specific criteria that have the purpose of achieving optimal conditions of efficiency and sustainability for the city.

Faced with the challenges that arise, such as interventions in historic cities that seek to renew in many cases the foundations on which a city is based, involving major changes in infrastructure and disturbances in the city's own functioning, urban planners face the need to preserve and treat scrupulously the essence of a city from its roots during the great processes of innovation that the 'Smart' movement entails. In search of a way to evade these obstacles, in recent years a new model of intelligent development has been cultivated based on the treatment and the establishment of intelligent incentives 'from scratch' in unaltered and non-urbanized territory.

The new prototype cities are capable of illustrating a potential for political and business development that fosters sustainability through technological processes and methods, the integration of new innovative infrastructures and systems to improve and enrich efficiency and reduce excessive expenditure of resources. However, these entail a new apparent problem in several aspects of urban development, new technologies often lead to similar and even higher levels of consumption in certain aspects, rather than adopting methods of development towards changes in patterns of production and consumption, and towards the reduction of ecological impacts. Existing cases have shown more conflict than benefits in the social aspects to be dealt with in the development of the urban structure, also losing the prestige and appreciation of the entities and communities on which it will depend, manifesting themselves as a burden of which they do not want to be responsible.

On the other hand, other models of innovation in the world of Smart Cities and Eco-Cities tend to emphasize above all the economic and ecological dimensions of sustainability, leaving aside social issues and community equity.

Urban development is proposed in order to deviate from the current path that positions the concept of an intelligent city solely as an application of new technologies in urban environments, in order to emphasize the idea that the development of solidarity and harmony of our contemporary cities should be based on the care and maintenance in the design of the relationship between the traditional structures of a city and the new information infrastructure, always taking care of the implications of the changes that have on the daily life of the citizens, and with the capacity to face the notions of sustainability and transition projects that include changes in the governing behaviours, the power, economic accessibility, participation and inclusion Social; a new model for social justice and human prosperity against elite interests and the suppression of values.

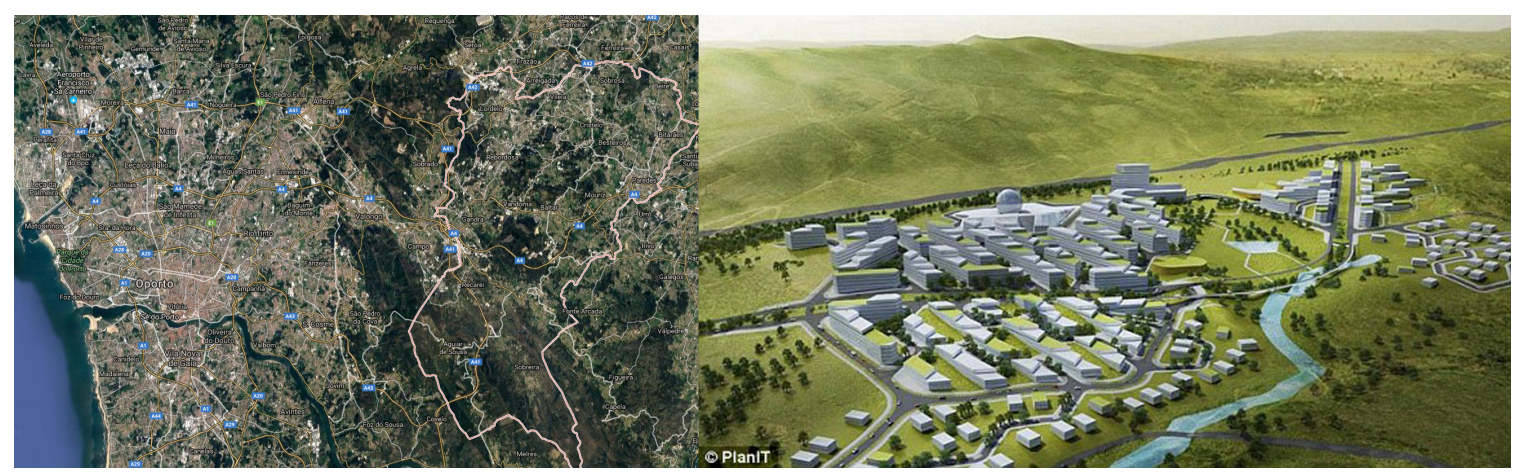

Figure 5. PlanIT Valley, Paredes, Porto, Portugal. Sources: Google and MailOnline (Science \& Tech) (http://www.dailymail.co.uk/sciencetech/article-2045577/Urban-OperatingSystem-revealed-run-PlanIT-Valley-super-city-Portugal.html) 


\section{References}

Al-Nasrawi, S., Adams, C. and El-Zaart, A. (2016) 'A conceptual multidimensional model for assessing smart sustainable cities', JISTEM - Journal of Information Systems and Technology Management 12(3), 541558.

Angelidou, M. (2014) 'Smart city policies: A spatial approach', Cities 41, S3-S11.

Copeland, E. (5 Oct , 2016) 'London 1854: the world's first smart city?' (http:// eddiecopeland.me/london-1854-worldsfirst-smart-city-john-snow/) accessed 7 June 2017.

Concilio G. and Rizzo F. (eds.) (2016) Human Smart Cities - Rethinking the Interplay between Design and Planning (Urban and Landscape Perspectives) (Springer: Cham, Suiza).

Dodgson, M., and Gann, D. (2011) 'Technological Innovation and Complex Systems in Cities', Journal of Urban Technology 18, 101-113.

Glasmeier, A. and Christopherson, S. (2015) 'Thinking about smart cities', Cambridge Journal of Regions, Economy and Society $8,3-12$.

Hollands, R.G. (2008) 'Will the real smart city please stand up? Intelligent, progressive or entrepreneurial?', City 12(3), 303-320.

Neirotti, P., De Marco, A., Cagliano, A.C., Mangano, G. and Scorrano, F. (2014) 'Current trends in Smart City initiatives: Some stylised facts' Cities 38, 25-36.

Oliveira A. (2015) 'Constructing Human Smart Cities' Keynote Lecturer presented on 22 May at the 4th International Conference on Smart Cities and Green ICT Systems - SMARTGREENS 2015 (http://www. insticc.org/portal/NewsDetails/TabId/246/ ArtMID/1130/

ArticleID/701/Constructing-Human-SmartCities.aspx) accessed 7 June 2017.

Ojo, A., Dzhusupova, Z. and Curry, E. (2016) 'Exploring the nature of the smart cities research landscape', in Smarter as the New Urban Agenda (Springer International Publishing) 23-47.
Snow, J. (1855) On the Mode of Communication of Cholera, 2nd Ed (John Churchill, New Burlington Street, London) (http://www. ph.ucla.edu/epi/snow/snowbook.html) accessed 7 June 2017.

Stimmel, C.L. (2016) Building Smart Cities: Analytics, ICT, and Design Thinking (CRC Press).

Townsend, A.M. (2013) Smart Cities: Big data, civic hackers, and the quest for a new utopia (W.W. Norton \& Company, New York).

Vojnovic, I. (2014) 'Urban sustainability: Research, politics, policy and practice', Cities 41, S30-S44. 